\title{
Contribuições da Teoria da Aceleração Social do Tempo para os Estudos em Jornalismo
}

\author{
Helder Prior \\ Tem pós-doutorado pela Faculdade \\ de Comunicação da Universidade de \\ Brasília, com bolsa do Plano Nacional de \\ Pós-Doutorado da Capes (PNPD/CAPES). \\ É licenciado e Doutor em Ciências da \\ Comunicação pela Universidade da \\ Beira Interior. \\ E-mail: heldeerprior@gmail.com.
}

\section{Caio Teruel}

Graduado em Jornalismo pela Universidade Federal de Mato Grosso do Sul (UFMS). Mestrando do Programa de Pós-Graduação em Comunicação da Universidade Federal de Mato Grosso do Sul.

E-mail: caioteruel05@gmail.com.
Resumo: $O$ artigo busca refletir a respeito das contribuições teóricas do sociólogo alemão Hartmut Rosa sobre a aceleração social do tempo para o campo do jornalismo. Assim, o pensamento aqui exposto parte das hipóteses de que existe em curso uma aceleração da produção jornalística que está em dessincronização com a capacidade receptiva dos leitores; e de que a exponencial produção informacional fragmenta o sentido dos fatos e facilita a desinformação. Em um primeiro momento, apresenta-se a teoria da aceleração temporal de Rosa e, em seguida, articula-se os pontos de contato possíveis com a comunicação jornalística e as categorias histórico-analíticas.

Palavras-chave: jornalismo, teoria da aceleração social do tempo, Hartmut Rosa, desinformação.

\section{Contribuciones de la Tesis de la Aceleración Social del Tiempo a los Estudios de Periodismo}

Resumen: Este artículo pretende reflexionar sobre los aportes teóricos del sociólogo alemán Hartmut Rosa acerca de la aceleración social del tiempo para el campo del periodismo. El pensamiento que se expone aquí parte de la tesis de que existe una aceleración permanente de la producción periodística que no está sincronizada con la capacidad receptiva de los lectores; y que la producción exponencial de información fragmenta el significado de los hechos y facilita la desinformación. Primero, se presenta la tesis de la aceleración del tiempo de Hartmut Rosa, y luego se articulan los posibles puntos de contacto con la comunicación periodística y las categorías histórico-analíticas.

Palabras clave: periodismo, tesis de la aceleración social del tiempo, Hartmut Rosa, desinformación.

\section{Contributions of the Theory of Social Acceleration for Journalism Studies}

Abstract: The article reflects upon the theoretical contributions of the theory of Social Acceleration, formulated by German sociologist Hartmut Rosa, for the field of journalism. The thought exposed herein departs from the hypotheses of an acceleration in the journalistic production, which is desynchronized with the readers' receptive capacity; and that the exponential information production fragments the meaning of the facts, thus enabling misinformation. The article presents Rosa's theory of temporal acceleration followed by an articulation of possible points of contact with journalistic communication and the historical-analytical categories.

Keywords: journalism, theory of social acceleration, Hartmut Rosa, disinformation. 
Em junho de 1897, Euclides da Cunha enviava o primeiro artigo ao jornal Estado de São Paulo. $O$ texto dizia respeito a sua cobertura da Guerra de Canudos. No momento do envio, o jornalista ainda não tinha obtido permissão de visitar a cidade de Canudos e, por isso, aguardava em Salvador (BA) para ir ao encontro de Antônio Conselheiro, líder místico do movimento. Esse texto seria o primeiro de uma série de 22 cartas/reportagens e 55 telegramas.

A partir desse momento, dado o contexto, o jornal paulista teria notícias suspensas pelo tempo. O envio de cartas, no fim do período do Brasil Império, demandava cerca de 12 dias para sua entrega. Os telegramas, enviados por rede elétrica, embora fossem mais rápidos, tinham questões técnicas mais restritas, como o pouco conteúdo que podiam veicular e seu custo mais alto (Maciel, 2001). A rede de telégrafos, inaugurada no Brasil em 1851, trazia em seu bojo uma era de transformações técnicas, culturais e informacionais.

O exemplo da cobertura da Guerra de Canudos realizada por Euclides da Cunha é sintomático das mudanças técnicas ocorridas na virada do século XIX para o século XX. Em pouco tempo, as cartas seriam substituídas. O vislumbrar do novo século foi um choque de mudanças em diversas esferas da vida social, inclusive no campo do jornalismo. Seu surgimento aos moldes industriais se consolidou no amanhecer dos anos 1900 e se transformou radicalmente no final desse século.

Os tempos atuais são opostos aos tempos de Euclides da Cunha. A produção informacional trabalha em níveis estratosféricos e diluída, não se resguardando apenas às cartas como plataformas ou aos jornais impressos. Neste cenário, o presente artigo busca olhar para a produção jornalística contemporânea pela perspectiva da teoria da aceleração social do tempo de Hartmut Rosa, encontrar os pontos de contato entre as categorias histórico-analíticas do teórico alemão e o campo jornalístico e sua formação sócio-histórica, e, por fim, refletir sobre os impactos da aceleração temporal no que tange ao consumo de notícias.

Assim, em um primeiro momento, o texto apresenta a teoria da aceleração temporal, suas delimitações e suas dimensões fenomenológicas, isto é, a aceleração da técnica, das mudanças sociais e do ritmo da vida, além das categorias de inércia apresentada pelo teórico alemão. Em um segundo momento, o texto busca situare refletir sobre a dinâmica e as consequências da aceleração para o campo jornalístico, de forma geral, tanto em termos de produção quanto em consumo.

\section{Sobre a Teoria da Aceleração Social do Tempo}

Hartmut Rosa é um sociólogo alemão que iniciou sua carreira na ciência política e que, por desvio acadêmico, lançou-se na teoria social. Discípulo de Charles Taylor e Axel Honneth, Rosa é atualmente professor de Sociologia Teórica na Universidade de Jena e, ao longo dos últimos 15 anos, tem se debruçado para compreender o movimento aceleratório na modernidade, além de suas consequências e alterações no tecido social.

Seu livro central acerca da teoria da aceleração social do tempo, publicado pela primeira vez no Brasil em 2019 pela Editora Unesp, intitulado Aceleração: A transformação das estruturas temporais na modernidade, é o principal tratado de Rosa sobre o desenvolvimento temporal ao longo da história moderna.

Na obra, o teórico analisa a história moderna pelo viés da temporalidade, e defende a tese principal de que a modernidade se constitui pela aceleração temporal e se desenvolve por ela. Assim, Rosa (2019) inaugura o conceito de estabilização dinâmica, que traz em seu cerne a concepção de que as sociedades modernas - por meio de uma aparente contradição paradoxal - apenas se desenvolvem com base no progresso constante e desenfreado. Sem adiantar o argumento central, cabe ainda trazer neste ponto os desdobramentos da estabilização pela dinamicidade. Rosa, portanto, acrescenta que existe uma tríade responsável por sustentar a aceleração dessa sociedade: crescimento material, incremento tecnológico e inovação cultural.

Embora a teoria proposta pelo teórico alemão seja atual e se desdobre principalmente na contemporaneidade, ela não direciona suas forças ao tempo 
atual. O cerne da pesquisa de Rosa se dá ao longo de toda a modernidade, de forma que o sociólogo bebe de diversas fontes com o intuito de enxergar as forças aceleratórias ocultas em teorias sociológicas de séculos anteriores. A base de seu pensamento vale-se de Marx, Weber, Durkheim e Simmel. Nesses teóricos, Rosa, como em uma arqueologia da aceleração, lança luz sobre fenômenos que comprovam seu pensamento e coadunam com sua tese. O teórico tenta, como afirma Tziminadis (2018), se aproximar do pensamento clássico da sociologia e dos modelos de análise já consagrados.

De Marx, teórico alemão do século XIX, Rosa capta o movimento aceleratório quando analisa o ciclo autodestrutivo que a dinâmica do capital impõe. Esse entendimento, por sua vez, dialoga diretamente com a conceituação do que Rosa chama de estabilização dinâmica, provando, portanto, a expansão constante e desenfreada das sociedades capitalistas ocidentais dos textos clássicos da sociologia.

Em Weber, a racionalização surge dos estudos sobre a ação política quanto a grupos protestantes. $O$ teórico alemão desenvolve a questão temporal como um problema de cunho de conduta puramente econômica, ou seja, formas viáveis e racionais de sua ação. Diferentemente de Marx, que enxerga uma causa estrutural, que se expande e foge do controle humano, Weber analisa o traço da racionalização e sua relação com o tempo sob um viés cultural.

De Émile Durkheim, sociólogo francês, o processo de diferenciação social contribui com a teoria da aceleração social de Hartmut Rosa enquanto uma consequência da modernidade, e não diretamente uma teoria para explicá-la, seja de maneira macro ou micro. Rosa adverte, assim, que a diferenciação social reduz os processos de interdependência, o que, por sua vez, desintegra o tecido social e cria uma situação de anomia. Vale aqui entendermos o processo na perspectiva de Rosa:

No entanto, após um olhar mais detido revela-se que sua intensa busca por novas formas de integração e solidariedade social é motivada, tal como as teorias sociais dos outros clássicos, pela experiência central de uma sociedade dinamizada, fragmentada e acelerada, o que resulta de uma condensação das relações sociais. Em sua análise das formas anômicas de divisão do trabalho, vistas como um dos maiores perigos do processo moderno de diferenciação, ele identificou a anomia social como consequência das demasiadamente rápidas mudanças sociais. Como resultado do ritmo elevado das mudanças, a consciência e as regras de interdependência social erodem antes que novas formas de integração social tenham tempo de se formar. Portanto, a mudança social e a crescente diferenciação não são, em si mesmas, um problema para a sociedade, mas sua temporalidade (demasiadamente) veloz. (Rosa, 2013, p. 51)

Por fim, em Simmel, a individuação, processo social centrado nas grandes metrópoles, condensa as formas e as dinâmicas da aceleração social do tempo. A individuação, diferentemente da diferenciação social, caracteriza-se como "a dissolução dos laços fixos que atam os sujeitos ao grupo, às ideias, às crenças e, consequentemente a um quadro de referência sociais que balizam seus percursos biográficos" (Tziminadis, 2018, p. 26). Simmel retrata, em sua conceituação de individuação, os impactos dos estímulos externos e internos que atuam sob a subjetividade dos indivíduos e a perda de conexão com os fatos e acontecimentos. Os apontamentos realizados por Simmel desguam, sobretudo, no diagnóstico realizado por Rosa no campo das patologias do tempo, uma consequência direta da aceleração social.

\section{Categorias Histórico-analíticas da Aceleração}

Desse modo, Rosa condensa a aceleração social em três dimensões fenomenológicas. Tais manifestações, embora estejam imbricadas entre si, podem ser lidas separadamente tanto pelo espectro material quanto pelo teórico. Essas categorias, por sua vez, ampliam o entendimento da penetração que a aceleração social possui no cotidiano dos indivíduos desde o início da modernidade, conforme aponta Hartmut Rosa. Além disso, o entendimento de tais categorias, trazido pelo teórico alemão, é o de independência e articulação autonômica entre as partes, pois possuem dinâmicas próprias. 
1 "A história da aceleração a ser contada aqui descreve o caminho da máquina a vapor, passando pelo domínio da energia hidráulica e do motor a combustão, até chegar à eletrotécnica, às tecnologias de produção industrial em massa, à linha de montagem e, por fim, à microtecnologia da era dos computadores. (ROSA, 2019, p. 144-145)

\section{Aceleração Técnica ${ }^{1}$}

Assim, de modo mais claro, Rosa elenca a aceleração técnica como um propulsor do aumento do ritmo temporal. Iniciada formalmente na Revolução Industrial mas com resquícios de tempos anteriores -, ela se firma como a categoria pensada para a supressão do tempo pelo espaço e pela automação técnica, o que deságua na aceleração temporal, tendo em vista a grande produção em curto tempo ou do encurtamento do espaço.

Sobre os meios de transporte, Rosa (2019) elabora uma tabela explicativa que elucida o aumento da velocidade, traçando uma linha cronológica que inicia antes mesmo da Revolução Industrial. Nesse período, em 1830, os navios a vela tinham capacidade de percorrer $16 \mathrm{~km}$ em uma hora. Nos anos de 1920, os trens conseguiam atingir a marca de $80 \mathrm{~km} / \mathrm{h}$. Na segunda metade do século XX, em 1965, os aviões a jato marcavam $1050 \mathrm{~km} / \mathrm{h}$.

Quando Rosa (2019) disserta acerca da aceleração técnica, a imprensa se encontra no cerne dessa questão. O efeito da supressão do espaço pelo tempo e, consequentemente, o avanço e a entrega das notícias em um tempo cada vez menor, propicia uma implosão da imprensa jornalística que se consolidava no local/regional desde o início (Tziminadis, 2018). Desse modo, a constante aceleração das técnicas potencializa uma dinamização maior na quantidade de informação, acarretando uma perda da consciência em relação aos fatos, tendo em vista o acúmulo de informações diárias. Se nos séculos XVII as informações se davam semanalmente, como aponta Franciscato (2014), as mudanças sociais e científicas do século XX transformaram a notícia em um produto não apenas diário, como momentâneo, com notícias novas, de diferentes partes do mundo, a cada minuto.

A circulação dos jornais produziu também uma relação temporal específica conforme o período do dia em que iam para as ruas. O surgimento regular de jornais matutinos e vespertinos foi uma adequação tanto a hábitos dos leitores quanto ao acirramento da concorrência pela possibilidade de levar ao público notícias mais recentes. A dinâmica do ritmo diário de vida nas grandes cidades, por sua vez, contaminou os jornais de tal forma que mesmo a existência de duas circulações diárias não inibia o recurso à edição "extra" durante o dia quando fosse necessário e conveniente. (Franciscato, 2014, p. 114)

\section{Aceleração das Mudanças Sociais}

Tendo pontuado a dimensão fenomenológica da aceleração técnica, cabe partir para a segunda dimensão proposta por Hartmut Rosa em sua teoria da aceleração social do tempo: a aceleração das mudanças sociais, em que se percebe um deslocamento da exterioridade para a subjetividade ${ }^{2}$. De acordo com Rosa, tal aceleração refere-se "à velocidade na qual, de um lado, práticas e orientações de ação, e, de outro, estruturas associativas e modelos de relação se modificam" (Rosa, 2019, p. 147). Outrossim, as transformações se autorregulam e adentram em um processo contínuo de aceleração.

A aceleração da mudança social pode ser definida como um aumento das taxas de expiração de experiências e expectativas orientadoras da ação, e como encurtamento dos intervalos de tempo que, para cada esfera funcional, de valor e de ação, podem ser determinados como presente. (Rosa, 2019, p. 152)

Assim, vislumbra-se, na sociedade da aceleração, no diagnóstico formulado por Rosa, uma contração em âmbitos sociais, ou seja, na política, na cultura, na economia, e na educação, e também nos arranjos familiares, dentre outros possíveis. As orientações que determinam as ações da vida cotidiana fluidificam-se em uma constante, alterando tanto perspectivas culturais quanto sociais. E Rosa continua:

Naturalmente é concebível, ainda, que esse processo de contração apresente, em distintas esferas, diferentes velocidades, e que ocorra uma inércia ou, em âmbitos sociais determinado, até mesmo um 'alongamento do presente', o que pode conduzir ao fenômeno da crescente dessincronização social. (Rosa, 2019, pp. 152-153) 
Nesse cenário de efervescência, o jornalismo, como observador histórico da primeira onda de aceleração social, relatou, dia após dia, as mudanças técnicas ocorridas no mundo, o que faz até os dias que correm. As transformações sociais, que se desenrolam com cada vez mais frequência, muitas das quais são impulsionadas pela aceleração técnica, chegam mais rápido ao consumo do indivíduo. Com base nas cinco categorias propostas por Franciscato, constrói-se, historicamente, o senso de atualidade e, com base nas três ressaltadas, esse senso dinamiza-se em torno da lógica da aceleração. Então, a notícia passa a ter um período de utilidade menor com o passar do tempo. Como ressalta o velho axioma, que se prova cada vez mais verdadeiro, "jornal velho só serve para embrulhar peixe".

\section{Aceleração do Ritmo da Vida}

Resta-nos tratar de uma última categoria histórico-analítica proposta por Rosa (2019) em que se manifesta o fenômeno da aceleração social do tempo: a da aceleração do ritmo da vida. Tal como as categorias supracitadas, essa pode ser analisada tanto de modo isolado como também de maneira concomitante às demais; todavia, possui relação intrínseca com a aceleração técnica e seus desdobramentos no cotidiano.

Essa categoria apresenta o aumento do número de ações e das experiências por tempo determinado, o que, por sua vez, como apontam Tziminadis (2018) e Rosa (2019), reflete na percepção de ausência de tempo pelos indivíduos. No âmbito do jornalismo, a aceleração do ritmo da vida pode ser compreendida pelo viés do aumento exponencial do número de notícias produzidas - e recebidas - por tempo determinado, tendo como consequência a ausência de conexão com os fatos envoltos na tempestade noticiosa por parte do receptor. Assim, suscita-se aqui a clássica passagem de Jean Jacque-Rousseau em seu livro Emílio ou da educação:

envolvido em um turbilhão social, basta que ele não se deixe arrastar nem pelas paixões nem pelas opiniões dos homens; veja ele pelos seus olhos, sinta pelo seu coração; não o governe nenhuma autoridade, exceto a de sua própria razão. Nessa posição, é claro que a multidão de objetos que o impressionam, os frequentes sentimentos de que é afetado, os diversos meios de satisfazer suas necessidades reais devem dar-lhe muitas ideias que ele nunca teria, ou que teria adquirido mais lentamente. (Rousseau, 2004, p. 356)

Rousseau (2004) esboça a sensação que se tem nos tempos que correm. O aumento exponencial da produção de acontecimentos cotidianamente lança o homem médio em um turbilhão que se constrói repleto de opiniões - muitas vezes de especialistas-, de fatos que se dizem imperdíveis, de jornais sensacionalistas, além dos canais de notícias dedicados ao jornalismo o dia todo. $O$ autor francês condensa a sensação do leitor contemporâneo do jornalismo ao enquadrar o indivíduo no turbilhão de mudanças sociais e tecnológicas difundindo ideias que alguém nunca teria, aqui entendidas como a ausência do jornalismo, ou suscitando que o leitor seja levado apenas pela razão, em uma espécie de contraponto à pós-verdade - conceito que possui demasiado uso no âmbito da comunicação política e que "refere-se a um tempo onde as narrativas sobre os acontecimentos do mundo se impõem aos próprios acontecimentos ou fatos ditos 'objetivos', mormente pela forma como são 'costuradas' e repetidas ou 'viralizadas' nos media digitais" (Prior, 2019, p. 12-13).

Nesse sentido, vale ressaltar também o jornalismo online e seus aplicativos para celular, que irrompem ao longo de toda a noite, segundo o entendimento de Crary (2016), e avançam cada vez mais no sono, vencendo a última barreira do capitalismo com suas notificações, também chamadas tecnicamente de push.

Logo, vale-se aqui do entendimento que Rosa (2019) usa para analisar a exacerbação da aceleração nessas três dimensões fenomenológicas citadas acima. De acordo com o teórico alemão, a ação da aceleração temporal provoca o que ele chama de limites críticos das faculdades sensíveis e cognitivas quando ele se propõe a analisar os movimentos, orgânicos ou não, que caminham na contramão da aceleração temporal. Para isso, o teórico elenca cinco categorias de inércia; embora interesse para estas páginas apenas uma, a do enrijecimento estrutural e cultural, passaremos rapidamente pelas demais. 


\section{As Categorias de Inércia}

A primeira categoria diz respeito aos limites de velocidade naturais, que são impostos de modo biológico e químico, ou seja, são inerentes e intrínsecos ao corpo humano. Nesse tópico, também está inclusa a capacidade cognitiva e subjetiva dos indivíduos; todavia, deve-se compreender, conforme aponta Tziminadis (2018), que a subjetividade ao longo da formação sócio-histórica da humanidade adquiriu certa elasticidade dada pela modernidade.

A segunda categoria trata das ilhas de desaceleração, lugares geográficos que ainda não foram tocados pelos fenômenos extremos da aceleração temporal. Tais lugares podem ser como tribos e grupos sociais que preferem o autoisolamento, como se estivessem parados naquele tempo e naquele lugar.

Na Modernidade Tardia, tais 'oásis de desaceleração' sofrem uma crescente pressão erosiva territorial, cultural e econômica. A lacuna temporal em relação aos ambientes passíveis e desejos de aceleração se torna cada vez maior e mais cara à medida que cresce seu 'efeito de frenagem' na interseção com o mundo social acelerado. (Rosa, 2019, p. 165)

As ilhas de desaceleração também podem ocorrer de maneira artificial, como lugares criados para relaxamento e tranquilidade, longe da vida conturbada da cidade e de seus barulhos, luzes e fluxos. Nesse tópico, é possível falar do jornalismo lento e de como o próprio campo reage à pressão exponencial sofrida pelo fator tempo. Esse movimento, surgido em 2007, reclama a ausência de investimento por parte das empresas jornalísticas em narrativas longas de não-ficção e acredita que a hegemonia das chamadas fast news deve chegar ao fim. No lugar das fast news, então, surgiria o slow journalism, preocupado com a qualidade das informações que chegam até os leitores sem que elas sejam prejudicadas pela pressão do tempo ou pelo horário de fechamento da edição (Nickel, 2018).

Deste modo, Rosa prossegue caracterizando a lentificação como efeito colateral disfuncional, um efeito cada vez mais comum nas sociedades modernas que se amplia em diversas esferas da vida social e cotidiana. Os exemplos mais caros dessa categoria de inércia podem ser observados nos congestionamentos do trânsito, que se outrora foram característica apenas de megalópoles, agora se tornam visíveis também em cidades de pequeno e médio porte. Todavia, essa categoria não se anexa apenas à técnica. É possível, como aponta Rosa (2019), enquadrar nela a exclusão dos trabalhadores da vida profissional no sentido de que "os motivos estruturais estejam ligados a um aumento da velocidade e da produtividade no processo de produção, de modo que os afetados... não consigam acompanhar o alto ritmo de atividade e inovação exigido na economia" (Rosa, 2019, p. 166). Vale ressaltar que a lentificação ocorre também como modo de dessincronização, ocorrida pela aceleração. Um exemplo claro disso é que em buscas realizadas em ferramentas de pesquisa online, há um descompasso de velocidade e a lentidão se impõe, acarretando uma freagem. Assim, o que era para ser rápido torna-se lento.

A desaceleração intencional, a quarta forma de inércia elencada por Rosa, pode ocorrer: 1. de forma ideológica; e 2. como estratégia de aceleração. A primeira categoria diz respeito às formas de desaceleração consciente que objetivam atender à demanda e a canalizam ao longo da história, constituída por movimentos que negam a modernização em suas diversas esferas. A segunda categoria diz respeito ao aumento da velocidade pela desaceleração, isto é, à parada consciente em prol do aumento das capacidades. Tziminadis (2018) cita o exemplo contemporâneo de empresas de tecnologias que buscam relaxar seus funcionários com videogames e espaços de descanso, dentre outras ferramentas.

Por último, Rosa (2019) apresenta-nos a categoria de inércia denominada enrijecimento estrutural e cultural. Tal categoria mostra-se como uma das mais paradoxais, pois parte da premissa de que, em sociedades modernas, o movimento temporal se inverte, isto é, do alto grau aceleratório surge o enrijecimento tanto estrutural quanto cultural. Diferentemente das outras categorias supracitadas de inércia, essa surge de modo orgânico no seio da sociedade e se difunde de 
modo silencioso, não permitindo mudanças e cristalizando todos os movimentos contemporâneos. Desse cenário em questão, Rosa dispõe da expressão que sintetiza a situação: frenesi em suspensão.

\section{O Jornalismo em Suspensão}

No campo do jornalismo, uma das propostas para enxergar esse movimento é a disfunção narcotizante. $O$ número exponencial de informações por tempo determinado, como visto em tópicos anteriores, provoca uma imobilidade física e mental, que, por sua vez, em tempos de fragmentação da esfera pública, incapacita o receptor e potencializa a difusão de falsas notícias.

Um mundo em crise que perpassa os telejornais, os websites, as notificações push, os podcasts e outros meios de comunicação, é assistido pelo cidadão médio diária e exaustivamente. As informações excessivas veiculadas em todas essas plataformas muitas vezes contrapõem-se e disputam com outras narrativas concomitantes em campos expressivos de diálogo. Uma resposta sociológica vem de José de Souza Martins ao narrar a vida cotidiana

As grandes certezas terminaram. É que com elas entraram em crise as grandes estruturas da riqueza e do poder (e também os grandes esquemas teóricos). Daí decorrem os desafios deste nosso tempo. Os desafios da vida e os desafios da ciência, da renovação do pensamento sociológico. Se a vida de todo o dia se tornou o refúgio dos céticos, tornou-se igualmente o ponto de referência das novas esperanças da sociedade. O novo herói da vida é o homem comum imerso no cotidiano. É que no pequeno mundo de todos os dias está também o tempo e o lugar da eficácia das vontades individuais, daquilo que faz a força da sociedade civil, dos movimentos sociais. (Martins, 2008, p. 52)

Martins esboça a situação na qual o homem comum se encontra em meio a diversas revoluções e rupturas. Assim, deve-se olhar de modo mais atento para não apenas o cotidiano da comunicação, mas para as mediações que daí decorrem. Desse modo, a temporalidade se estabelece como uma lente teórica ímpar para não apenas analisar o fazer jornalismo nos tempos atuais, mas também para reinventar a prática da comunicação e suas estratégias.

Mas a temporalidade vai além disso, pois no cenário até aqui esboçado, o que se tem, de fato, é um mundo em crise sendo transmitido 24/7 em diversas plataformas, concomitantemente a um regime de atenção difuso no qual o jornalismo caminha a passos lentos. Isto é, os motores propulsores da aceleração social do tempo no campo do jornalismo, que deriva das categorias histórico-analíticas de Rosa (2019), se consolidam no campo da comunicação no entendimento da hiperconcorrência entre as empresas jornalísticas que no tecido social da atualidade disputam a atenção demasiadamente fragmentada do leitor. Isso decorre, de modo claro, da multiplicação das fontes de informação, da ubiquidade dos fatos e da consolidação do jornalismo como setor industrial de grande importância.

Os autores canadenses Jean Charron e Jean de Bonville, em sua obra Natureza e transformação do jornalismo (2016), olham o aumento da oferta do mercado midiático com bons olhos, no sentido do aumento da possibilidade de escolha, mas ressaltam algo caro para a obra de Rosa (2019), que é o regime de atenção. Para os autores canadenses, "a dispersão da atenção pelo crescimento da oferta limita a possibilidade de a mídia atrair grandes audiências, enquanto as condições técnicas de captação da atenção se tornam limitadoras para ela, já que pode perder a atenção do consumidor a qualquer momento" (Charron \& Bonville, 2016, p. 382).

Nesse percurso cognitivo de atenção, ocorre, por sua vez, a fragmentação do sentido pela duração da ação jornalística. Charron e Bonville (2016) trazem a questão ao analisar as diferenças de atenção entre pessoas jovens e mais velhas. Pessoas mais velhas necessitam de uma ligação do começo ao fim do programa para apreenderem seus sentido e significado. Diametralmente opostos a esse padrão, os jovens, nascidos em uma sociedade abundante em produtos midiáticos e digitais, consomem, ao analisar produtos televisivos, programas que trazem seu sentido de 
modo imediato, de maneira a facilitar o consumo fragmentado. Assim, "a televisão sequencial e programada dos primórdios cede progressivamente o lugar à TV da hiperconconcorrência, interativa e sincrética ...como é a navegação na web" (Charron \& Bonville, 2016, p. 382).

Destarte, como hipótese central de investigação deste artigo, com base na bibliografia supracitada, resume-se no gráfico abaixo nossa ideia central. Quanto maior o fluxo informacional derivado da aceleração temporal e de suas respectivas manifestações no plano fenomênico, maior será sua fragmentação de sentido e, portanto, maior será a possibilidade de haver desinformação sobre os fatos. Todavia, nem sempre um grande fluxo informacional leva à fragmentação de sentido.

\section{Gráfico 1 Gráfico explicativo}
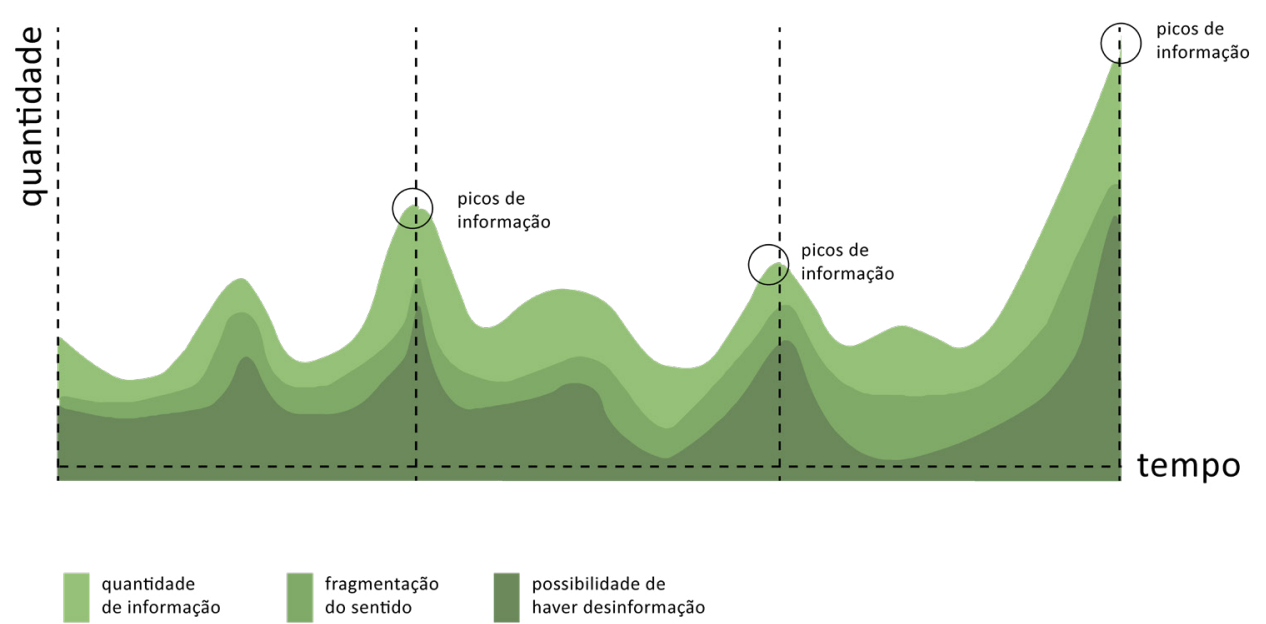

Nota: Elaborado pelos autores.

É possível haver, como nos mostra o gráfico, momentos que, embora tenham em sua constituição um alto grau de informação, não elevem a fragmentação de seu sentido. Isso pode ocorrer por diversas razões, como o modo de abordagem do fato pela mídia hegemônica, o local de ocorrência, o agendamento midiático, o nível de reconhecimento social das pessoas envolvidas no acontecimento e o não engajamento do público.

Entende-se aqui como informação o produto noticioso contemporâneo desenvolvido por jornalistas em um contexto que se propõe a relatar acontecimentos - no sentido preconizado por Sodré (2012). Parte-se, portanto, do entendimento de um aumento exponencial desses relatos, que se compreende aqui como o aumento do fluxo informativo. De acordo com Sodré:

A informação púbica, sempre a meio caminho entre a produção e o lazer, insere-se na lógica moderna de estruturação do tempo social. A temporalização operada pelo jornalismo realiza uma síntese das continuidades, mudanças e passagens, que, de modo disperso ou caótico, definem o cotidiano. A periodização, que orienta a sequencialidade temporal de jornais e revista (afim à linearidade e sequencialidade do livro) é um exemplo de vinculação da experiência do tempo com os fatos da comunidade). (Sodré, 2012, p. 87)

A periodização que Sodré menciona se dissolve no cenário de aceleração temporal, pois transforma as fronteiras em campos de hibridização, desintegrando o que outrora havia, isto é, marca-se o início de um novo dia com a leitura do jornal impresso, o meio-dia, com o jornal televisivo da hora do almoço ou a hora do jantar com o jornal da noite. A aceleração técnica permite o embaçamento de fronteiras temporais por meio do jornalismo, pois todos os momentos podem ser preenchidos com o consumo jornalístico em suas diferentes plataformas. O fluxo informacional é incessante, apresentando-se "como um fluxo heterogêneo, senão estilhaçado, de dados significativos da existência, sempre sob modalidades de discurso afins ou compatíveis com os microuniversos do quotidiano e sob a regência de ritmos ditados pela produção industrial" (Sodré, 2012, p. 87-88). 
Desse modo, o jornalismo em suspensão - para fazer alusão ao frenesi em suspensão de Hartmut Rosa - se codifica pela disfunção narcotizante contemporânea, categorizada principalmente pela base temporal e pela aceleração tecnológica, social e do ritmo da vida, propagandeada e noticiada pelo jornalismo atual. Nesse sentido, o regime cognitivo de atenção que fragmenta o sentido pela duração abre brechas para desinformação e notícias falsas, que derivam, em parte, da fragmentação da esfera pública, que multiplica os centros de debate e cria bolhas sociais e informacionais.

\section{Algumas Ideias Finais}

A teoria da aceleração social do tempo, proposta pelo teórico alemão Hartmut Rosa, é demasiadamente abrangente e não se esgota em apenas poucas páginas. Ao situar a aceleração temporal frente aos estudos em jornalismo, cria-se, pois um crescente fértil de possibilidades de análises. Desse modo, o que foi exposto até aqui traz no bojo algumas de suas principais categorias histórico-analíticas e, portanto, a fenomenologia da aceleração em seu cerne, manifestada na técnica, nos movimentos sociais e nos ritmos da vida. Além disso, vislumbra-se também, nestas páginas, o percurso teórico-histórico da aceleração nas teorias clássicas da sociologia de Marx, Durkheim, Simmel e Weber. Nesse sentido, discorre-se, também, sobre as categorias de inércia, que se desenvolvem em contraponto ao estado de extrema aceleração temporal.

Assim, nesse panorama delimitado, o campo do jornalismo se expande historicamente, conforme a aceleração técnica avança, e esbarra nos movimentos sociais e no ritmo da vida dos indivíduos, o que insere o fenômeno aceleratório em um ciclo retroalimentar. Nesse ciclo, por fim, o cidadão médio se encontra no turbilhão de mudanças e avanços, que recorrentemente o confronta ao novo, ao moderno, de forma que, em um longo processo de enculturação, o indivíduo adapta-se e se prepara para as próximas mudanças que ocorrem rapidamente na contemporaneidade.

Desde o século XIX, as mudanças têm sido apresentadas diariamente por meio das páginas de jornais impressos e revistas noticiosas. Conforme a técnica avança, o mercado jornalístico adentra cada vez mais no cotidiano e na intimidade dos indivíduos sociais por meio de notificações push, plantões e redes sociais, em um ritmo frenético de publicação, acarretando, por fim, em uma saturação da consciência do receptor.

Nesse panorama, a aceleração social do tempo se desenvolve no jornalismo por meio da produção exponencial de fatos e acontecimentos que, por fim, são descarregados $24 / 7$ nos indivíduos, conforme a ideia de Crary (2016), alterando as capacidades cognitivas e subjetivas dos receptores no que tange à disfunção narcotizante, em um estado permanente de fragmentação do sentido, ao passo que potencializa a disseminação de falsas notícias, tendo em vista os moldes de operação das múltiplas esferas públicas na contemporaneidade.

\section{Referências}

CHARRON, J., \& DE BONVILLE, J. (2016). Natureza e transformação do jornalismo. Insular.

CRARY, J. (2016). 24/7: Capitalismo tardio e os fins do sono. Ubu.

FRANCISCATO, C. E. (2014). O jornalismo e a reformulação da experiência do tempo nas sociedades ocidentais. Brazilian Journalism Research, 10(2), 96-123. https://doi.org/10.25200/BJR.v10n2.2014.741

MACIEL, L. A. (2001). Cultura e tecnologia: A constituição do serviço telegráfico no Brasil. Revista Brasileira de História, 21(41), 127-144. https://doi.org/10.1590/ S0102-01882001000200007 
MARTINS, J. S. (2008). A sociabilidade do homem simples (2a ed.). Contexto.

NICKEL, B. (2018, novembro). O que é lento no slow journalism? Uma análise da sua relação com o tempo [Trabalho apresentado]. 16을 Encontro Nacional de Pesquisadores em Jornalismo, São Paulo, SP, Brasil. http://hdl.handle.net/10183/201052

PRIOR, H. (2019). Populismo e desinformação em tempos de pós-verdade. [Trabalho apresentado]. 17을 Encontro Nacional de Pesquisadores em Jornalismo, Goiânia, GO, Brasil.

ROSA, H. (2013). Social acceleration: A new theory of modernity. Columbia University Press.

ROSA, H. (2019). Aceleração: A transformação das estruturas temporais na Modernidade. Unesp.

ROUSSEAU, J-J. (2004). Emílio ou da educação (3a ed.; R. L. Ferreira, Trad.). Martins Fontes.

SODRÉ, M. (2012). A narração do fato: Notas para uma teoria do acontecimento. Vozes.

TZIMINADIS. J. L. F. (2018). Frenesi em suspensão: Em direção a um modelo crítico a partir da teoria da aceleração social de Hartmut Rosa (Dissertação de mestrado, Faculdade de Ciências e Letras, Universidade Estadual Paulista). Biblioteca Digital de Teses e Dissertações da Unesp. https://repositorio.unesp.br/bitstream/ handle/11449/153611/tziminadis_jlf_me_arafcl.pdf?sequence=5\&isAllowed=y 